\title{
Capital Budgeting Techniques in SMEs: A Literature Review
}

\author{
Zahida Sarwary \\ Kristianstad University \\ Lund University
}

This paper provides a systematic literature review of research in the field of capital budgeting techniques (CBT) among small-and medium-sized firms. In total, 26 studies published between 1964 and 2017 were reviewed. It covers three areas: the type of CBT that have been used across sizes and locations; determinants associated with the choice of CBT; and the methods and analysis techniques used in previous studies. SWOT analysis was done to systematise the findings and to identify the shortcoming and strengths in existing literature. For each area, potential areas of research to further the field are suggested.

\section{INTRODUCTION}

Scholars argue that SMEs (small- and medium-sized Enterprises) are the backbone of the economy and a vehicle of employment (e.g. Peel and Bridge, 1996). A particular concern regarding SMEs is that they face constraints in reaching their optimal size because they lack access to capital markets (Peel and Bridge, 1996). Earlier, Brigham (1995) had argued that it is crucial for SMEs to make an appropriate evaluation of their potential investments by using capital budgeting techniques (CBT). CBT are argued to be fundamental for effectively selecting potential investments (Verbeteen, 2006) because they enable capital to be allocated to productive investments (Arnold and Panos, 2000). The importance of SMEs using appropriate CBT are further argued by Block (1997). He suggests that due to scarce resources, it is more important for SMEs than for large firms to use appropriate evaluation tools because they do not have same possibility of diversifying risk in a portfolio consisting of several investments. Over the years, a number of CBT have evolved to guide the evaluation of investments (Hartwig, 2012). The use of CBT among SMEs has long been of interest to scholars (Soldofsky, 1964; Luoma, 1967; Grablowsky and Burns, 1980, Drury and Tayles, 1996; Lazaridis, 2004; Harjoto and Paglia, 2012; Andor et al., 2015).

Previous research has generally divided CBT into two categories: sophisticated capital budgeting techniques (SCBT) and non-sophisticated capital budgeting techniques (NSCBT) (e.g. Mukherjee and Rahahleh, 2013). This categorisation of the CBT is rooted in a dominant stream of literature that suggests that investments chosen based on SCBT will outperform those based on NSCBT (e.g., Gitman and Forrester, 1977). Scholars started recommended the use of SCBT to practitioners in the late $16^{\text {th }}$ century. By mid- $19^{\text {th }}$ century, there was increased agreement that SCBT was superior, which led to the categorisation of CBT into sophisticated and non-sophisticated. Today, the use of these two categories has been normalised (cf Haka, 2006). Researchers argue that superiority of SCBT lays in them being oriented mainly towards benefiting shareholders, being focused on the long term, considering a comprehensive 
amount of information in the evaluation, considering a market- driven investment risk, and being oriented towards value-profit maximisation (Kaplan and Atkinson, 1998). NSCBT, however, are focused on the short term, appropriate for use where there is less easily estimated long-term information, consider risk in terms of securing short-term payoff, and have a liquidity orientation. Consequently, researchers claim that the use of NSCBT will not provide the decision maker with enough information to make a rational choice (cf Gitman and Forrester, 1977).

For some time research in the field of CBT has been dominated by descriptive normative research and there has been a lack of exploratory research. Because of the focus on descriptive normative research, numerous scholars have mapped the extent to which SMEs use SCBT and NSCBT (see critique by Daunfeldt and Hartwig, 2014). Many studies show that SMEs prefer using NSCBT (e.g. Corner, 1967; Arnold and Panos, 2000; Block, 1997; Peel, 1999; Lazaridis, 2004; Danielsson and Scott, 2006; Andor et al., 2015; Harjoto and Paglia, 2012); A few show that SMEs prefer using SCBT (e.g. Trahan and Gitman, 1995; Maquieira et al., 2012). Others show that SMEs use a mix of NSCBT and SCBT (e.g. Williams, 1969; Arnold and Panos, 2000; Peel and Wilson, 1996): Drury and Tayles, 1996). Overall, the studies that map the use of CBT among SMEs show that SMEs prefer using NSCBT instead of SCBT. This contradiction between scholars and practitioners preferences of CBT is referred to as a theory-practice gap in the literature (e.g. Andor et al., 2015; Graham and Harvey, 2001).

Scholars have criticised the normative way of approaching CBT and claimed that research has had a wider focus on the theoretical rationality of CBT than on expanding the empirical research (e.g. Sarwary and Umans, 2017). For instance, despite the many recommendations to use SCBT (Gitman and Forrester, 1977), firms facing financial constraints would benefit from using NSCBT, which would allow them to secure their survival (Soldofsky, 1967). While there might be some sophistication in NSCBT, it is not as recognised as being as sophisticated as SCBT. What is considered to be the sophisticated CBT to use should instead be depends upon the context in which firm is operating in (Sarwary and Umans, 2017). Hence, the purpose of this paper is to systematise what we know so far from the literature on the use of CBT among SMEs and to suggest potential ways forward in the field, which several scholars have called for (e.g. Northcott, 1991).

To achieve this purpose, the paper will provide a systematic literature review of the use of CBT among SMEs, covering the development from $1964^{1}$ to 2017. The systemised structure of this review is based on a SWOT analysis inspired by Jackson et al. (2003) that identifies the strengths, weaknesses, threats and potential opportunities for future research that might overcome the shortcomings in current research. The systematic literature review is based on 26 papers.

The paper first presents the methodology and then the choices of CBT made by different types of SMEs. This is followed by a summary of the determinants behind the choices of CBT and a categorisation of these determinants with a reference to a theoretical framework. Lastly, the paper considers methodologies used, followed by a conclusion.

\section{METHODOLOGY}

\section{Search Criteria}

In order to capture a wide range of studies exploring the use of CBT among SMEs, a comprehensive search for papers from 1960s to the present was done. The selection criteria was as follows: (a) empirical studies; (b) if a study covered both large firms and SMEs, it was included if 1) the results distinguished between the different sized firms or 2) where the results did not distinguish between the SMEs and large firms, the sample had to be dominated by SMEs (at least $90 \%$ ).

\section{Search Strategy}

The search strategy occurred in four stages to capture the development of SMEs' use of CBT. In the first stage, a traditional string search technique was used, following the Boolean system. The following databases were searched: Sciencedirect (6), JSTOR (1), Emerald (1), Springer (0), Taylor and Francis (3), Wiley online library (4) and EBSCO (6). Since capital budgeting practices are one of the area's most 
frequently written about, the following search words were used: "capital budgeting technique" AND (Small firms OR Medium firms OR SME). Abstracts were screened for the first exact term "capital budgeting techniques" and for the second term (Small firms OR Medium firms OR SME); full texts were allowed to capture papers that did not include the group investigated in the abstract. Further, to find relevant papers, the results the papers were screened to see if they provided empirical data on CBT used. This resulted in a total of 21 papers.

To capture studies not included in the databases, in the second stage, snowballing was performed, in Google Scholar using the same search words as for the databases. This resulted in an additional 7 papers, for a total of 28 .

In third stage, the screening technique captured studies presented in the papers found in stages one and two. These articles are mainly from the ' 60 s to the ' 80 s. The majority were not available electronically and so were ordered in print. This resulted in an additional 11 papers, for a total of 39.

Lastly, the journals in which these papers were published were checked to ensure they met the requirements of the Norwegian Register for Scientific Journals, Series and Publishers. As a result 13 papers were excluded, so 26 papers were reviewed in this study. The choice to only include papers ranked as either 1 or 2 in the Norwegian list ${ }^{2}$, which was made to exclude papers of low quality. However, the papers from ' $60 \mathrm{~s}$ and ' $70 \mathrm{~s}$, which were not included in the Norwegian list, were included anyway to capture the development from start.

\section{FINDINGS}

\section{Types of CBT Used by SMEs}

Previous research has mainly divided CBT into two categories: SCBT and NSCBT. CBT such as the net present value (NPV), internal rate of return (IRR), modified internal rate of return (MIRR), profitability index (PI) and real options (RO) are usually included in SCBT. CBT such as the payback method (PB), accounting rate of return (ARR), return on assets (ROA), return on equity (ROE), return on investment (ROI) and discounted payback (DPB) are usually included in NSCBT (Klammer, 1972; Sarwary and Umans, 2017). Table 1 shows the extent to which various CBT are used by SMEs. It further shows which CBT are commonly included in the studies. Due to their unclear results, Lima et al (2017) was excluded from the analysis in this section and the percentage count in table 1; this study has been marked as NC (not clear).

\section{Summary of Major Findings}

The most common CBT in the studies covered in this review is PB (all studies), followed by ARR, which was covered in 92\% of the studies included studies (all except for Williams, 1969 and Harjoto and Paglia, 2012) and NPV, which was covered in $72 \%$ of the included studies (all studies except for Luoma, 1967; Corner, 1967; Pattillo, 1981; Peel and Wilson, 1996; Danielsson and Scott, 2006; Harjoto and Paglia, 2012; Andor et al., 2015). The least common CBT are MIRR, which were covered in 4\% of the studies (Trahan and Gitman, 1995) and PI, which was covered in 36\% of the studies (McIntyre and Coulthurst, 1985; Trahan and Gitman, 1995; Vos and Vos, 2000; Graham and Harvey, 2001; Lazaridis, 2004; Brounen et al., 2004; Maquieira et al., 2012; Rossi, 2014; 2015). Only 16\% of the studies gave respondents the option of choosing "no technique" (Lazaridis, 2004; Grablowsky and Burns, 1980; Runyon, 1983; Peel and Wilson, 1996).

\section{Strengths}

In the studies included, the use of NSCBT dominated. Payback had the highest percentage of use among SMEs (92\%), while the ARR dominated the remaining 8\%. This indicates that there is a consistency in which CBT are preferred by SMEs. This consistency might further indicate that there may be a sophistication in using NSCBT among SMEs. All firms that used at least one CBT used others. Rossi (2014) implies that using a combination of CBTs, and hence evaluating the investment from more than one angle, could enhance the validity of the choice to accept or reject a project. 


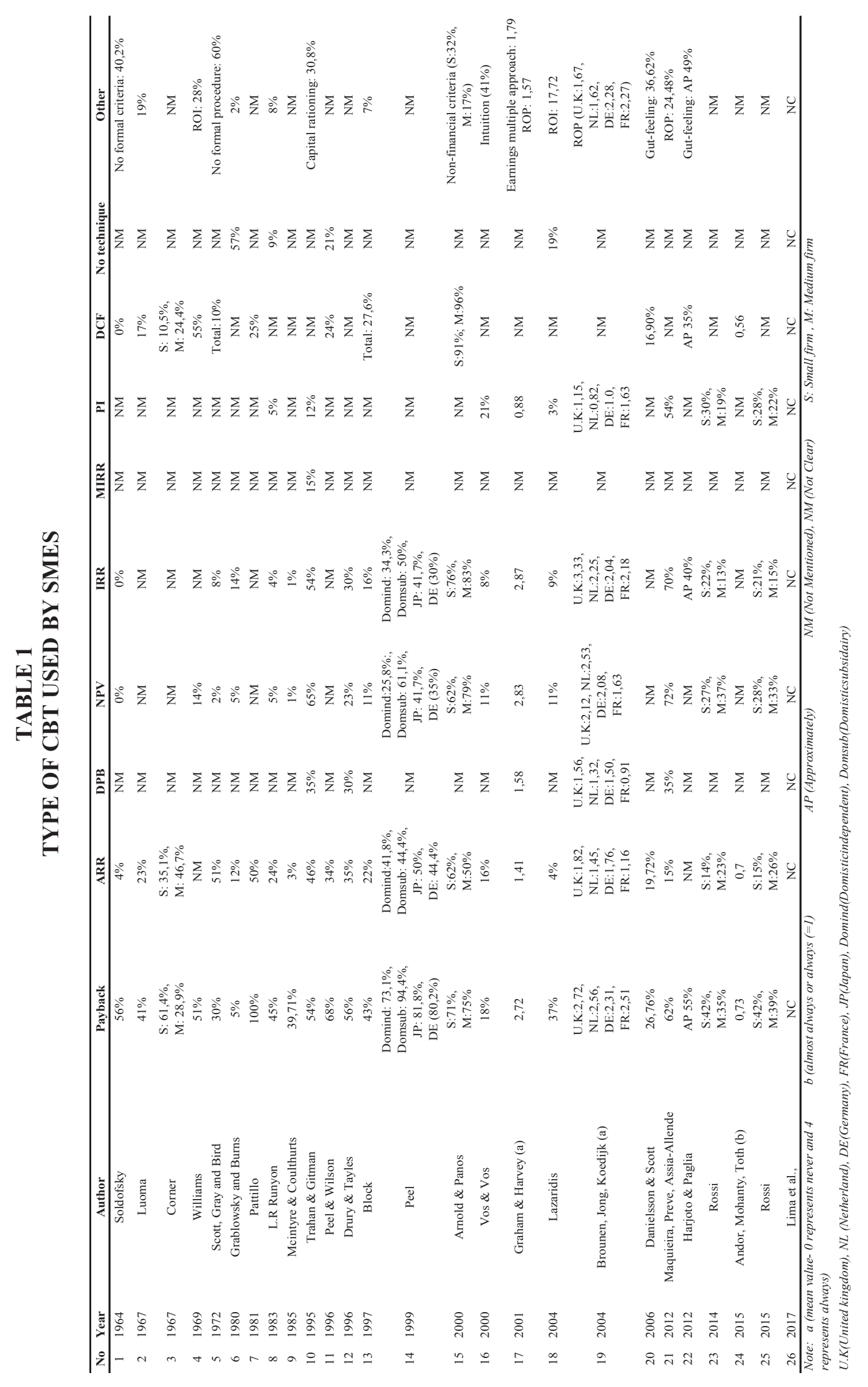

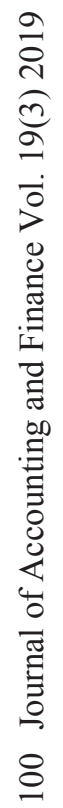


Table 1 further shows that the use of SCBT among SMEs has increased with time, indicating that SMEs have become more advanced in their evaluations of investments. The choice to use no formal criteria for appraising investments was common in the early '60-'70s (Soldofsky, 1964; Scott et al., 1972), but with time was replaced by the use of more advanced techniques. A few studies show that decision makers use gut feelings as a CBT instead of normative rationality when evaluating investments (Danielsson and Scott, 2006; Vos and Vos, 2000; Harjoto and Paglia). Ekanem et al. (2007) argue that using gut feeling in investment appraisals is common among SMEs, and that the gut feeling is based on the extensive learning experience of the decision makers and its surroundings. Suggesting that, gut feeling could in many cases be beneficiary, because in a smaller corporation the decision maker have the possibility to intuitively get to know its surrounding (Ekanem \& Smallbone, 2007).

\section{Weaknesses}

Despite a wide range of CBT being available for the respondents in the studies, the results often showed that the studies lacked in covering non-financial criteria. Thus, while the literature had been focusing on quantitative financial CBT, the respondents indicated that qualitative techniques could be of importance. For instance, Soldofsky (1964) and Scott et al. (1972) show that the decision makers do not have a regular planned procedure. Arnold and Panos (2000) show that more than $30 \%$ of small firms use various non-financial criteria, while Danielsson and Scott (2006) show that decision makers' gut feeling is what majority of the small firms use when deciding to reject or accept an investment.

\section{Opportunities}

As Table 1 indicates, SMEs have increased their use of SCBT over time. Future research should focus on exploring the incentives behind the increased use of SCBT. Furthermore, it appears that several SMEs do not use any CBT (Grablowsky and Burns, 1980; Lazaridis, 2004; Peel and Wilson, 1996), making it interesting to explore why the current CBT developed in the literature are irrelevant for some SMEs. Lastly, future studies should focus upon exploring non-financial criteria because SMEs make a high use of non-financial criteria when evaluating investments (Arnold and Panos, 2000). For instance, Segelod (1998) argues that the quantitative financial criteria become more relevant as the firm grows in size. The same author further suggests that the CBT developed in the literature become more relevant when the firm goes from being horizontal to vertical in its structure, and that in a horizontal firm, non-financial criteria could be provide a greater benefit when used in making decisions.

\section{Threats}

Continuing to follow the normative stream of research that recommends that SMEs use SCBT despite their circumstances could result in a lack of understanding about how SMEs evaluate their potential investments. When the respondents in the studies were asked about how they made their choices, the choices for responses were dominated by CBT developed by scholars. In addition, $36 \%$ of the studies did not give the respondents an option to reflect on whether they used other CBT (Corner, 1967; Pattillo, 1981; McIntyre and Coulthurst, 1985; Peel and Wilson, 1996; Drury and Tayles, 1996; Peel, 1999; Rossi, 2014; 2015; Andor et al., 2015). Furthermore, the studies took for granted that all SMEs use CBT; only $16 \%$ of the studies allowed the respondents to choose "no technique" (Lazaridis, 2004; Grablowsky and Burns, 1980; Runyon, 1983; Peel and Wilson, 1996). Grablowsky and Burns (1980), for example, show that $57 \%$ of the respondents do not use any CBT, indicating that either SMEs do not evaluate their investments or that they do not find the CBT developed from the literature suitable. Hence, in order to understand the evaluation of investments by SMEs, future research should explore the circumstances of SMEs that do not use of CBT developed from the literature.

\section{Criteria Used by Studies}

The criteria used in the empirical studies performed among SMEs choice of CBT has been mainly 1) concentrated to few geographic areas, 2) has had a spread definition of SMEs and 3) had a focus on which primary CBT that has been chosen. Thus, table 2 presents an overview of some of the criteria used by the studies as well as their findings on the primary CBT chosen by the SMEs. The types of CBTs follow the 
categorisation in previous research of NSCBT and SCBT (e.g. Graham and Harvey, 2001). It further includes whether the SMEs choose a combination of these categories and details of the definitions of SMEs.

In addition, it only presents studies that have stated which CBT were used in combination; those studies that presented a combination but did not provide these details are marked as NC (not clear) and therefore not counted as combination in the table. Table 2 also includes the definition of size used by the studies. The decision to include size is based on Ang and Dukas (1991), who argues that in order to compare the SMEs across the studies, one has to consider the definition specific to each country. Ang and Dukas (1991) further emphasises that the definition of size varies among countries, which could lead to misleading interpretations when comparing the studies, where, for instance, a small firm in Anglo-Saxon countries fits the definition of a large firm in European countries. Anglo-Saxon countries include Australia, Canada, New Zealand, and the USA (Atkinson \& Leigh, 2013). Whereas, UK (United Kingdom) includes the following countries: England Scotland, Ireland and Wales (Naidoo \& Campbell, 1988),

TABLE 2

CRITERIA USED BY STUDIES

\begin{tabular}{|c|c|c|c|c|c|}
\hline No & Location & Turnorer (Million) & Employees & Primary CBT used & Combination \\
\hline $\begin{array}{l}1 \\
2\end{array}$ & $\begin{array}{l}\text { US } \\
\text { US }\end{array}$ & $\begin{array}{l}\text { NM } \\
<55\end{array}$ & $\begin{array}{l}20-1000(20-249) \\
500-1000\end{array}$ & $\begin{array}{l}\text { NSCBT } \\
\text { NSCBT }\end{array}$ & $\begin{array}{l}\mathrm{NM} \\
\mathrm{NM}\end{array}$ \\
\hline 3 & UK & NM & $\begin{array}{l}\text { Small }<100 \\
\text { Medium }<100-499\end{array}$ & $\begin{array}{l}\text { Small: NSCBT } \\
\text { Medum SCBT }\end{array}$ & $\mathrm{NM}$ \\
\hline 4 & us & $\mathrm{NM}$ & NM & NSCBT \& SCBT & NM \\
\hline 5 & us & $<s_{1}$ & $\mathrm{NM}$ & NSCBT & NM \\
\hline 6 & us & $<\$ 5$ & $\mathrm{NM}$ & None & NSCBT \& SCBT \\
\hline 7 & us & $<\$ 6-35$ & MM & NSCBT & NSCBT \& SCBT \\
\hline 8 & us & s0.5-1 & NM & NSCBT & NM \\
\hline 9 & UK & Medium: f1.4.5.57 & Medium: $50-250$ & NSCBT & NSCBT \& SCBT \\
\hline 10 & us & $<\$ 750$ & $\mathrm{NM}$ & SCBT & $\mathrm{NM}$ \\
\hline 11 & UK & $\mathrm{NM}$ & -50 & NSCBT & NSCBT \& SCBT \\
\hline 12 & UK & Small: $<\{30$ & NM & NSCBT & NSCBT \& SCBT \\
\hline 13 & US \& Canada & $<55$ & $<1000$ & NSCBT & NM \\
\hline 14 & UK, Japan \& Germany & $\mathrm{NM}$ & $\begin{array}{l}\text { Small: 10-99 } \\
\text { Medium: } 100-499\end{array}$ & NSCBT & $\mathrm{NC}$ \\
\hline 15 & UK & $\begin{array}{l}\text { Small: } f 40-60 \\
\text { Medium: } 6207-400\end{array}$ & $\mathrm{NM}$ & NSCBT & $\begin{array}{l}\text { Small: NSCBT \& SCBT } \\
\text { Medum NSCBT \& SCBT }\end{array}$ \\
\hline 16 & New Zealand & $\mathrm{NM}$ & $\mathrm{NM}$ & NSCBT & NM \\
\hline 17 & us & $<\$ 1000$ & NM & NSCBT & $\mathrm{NM}$ \\
\hline 18 & Cyprus & $<\epsilon 5$ & $\mathrm{NM}$ & NSCBT & $\mathrm{NM}$ \\
\hline 19 & Netherlands, Germany, France \& UK & $<\$ 1000$ & MM & NSCBT & NM \\
\hline 20 & US & $\mathrm{NM}$ & $<50$ & NSCBT & $\mathrm{NC}$ \\
\hline 21 & Latin America & $\begin{array}{l}\text { Small: } \varangle 1000 \\
\text { Medium: NC }\end{array}$ & $\mathrm{NM}$ & SCBT & $\mathrm{NC}$ \\
\hline 22 & US & $\begin{array}{l}\text { Small: } \leqslant 0.5 \\
\text { Medium: } \$ 0.5-5\end{array}$ & $\mathrm{NM}$ & NSCBT & $\mathrm{NM}$ \\
\hline 23 & Italy, France \& Spain & $\mathrm{NM}$ & $<250$ & $\begin{array}{l}\text { Smalt: NSCBT } \\
\text { Medum SCBT }\end{array}$ & NM \\
\hline 24 & Central \& Eastern Europé & $\begin{array}{l}\text { Small:€1-9 } \\
\text { Medium.€10-50 }\end{array}$ & $\begin{array}{l}\text { Small:25-50 } \\
\text { Medium: } 51-250\end{array}$ & NSCBT & NSCBT \& SCBT \\
\hline 25 & Italy & $\mathrm{NM}$ & $\mathrm{NM}$ & $\begin{array}{l}\text { Small:NSCBT } \\
\text { Medum:SCBT }\end{array}$ & $\mathrm{NM}$ \\
\hline 26 & Brazil & $\begin{array}{l}\text { Micro: }<R S 0.36 \\
\text { Small firms: } \ll S 3,6\end{array}$ & $\mathrm{NM}$ & NCBT & $\mathrm{NM}$ \\
\hline
\end{tabular}




\section{Summary of Major Findings}

Most studies only looked at the primary CBT used by SMEs without considering which CBT were used in combination; these accounted for $73 \%$ of the studies (all studies except for: Andor et al., 2015; Arnold and Panos, 2000; Drury and Tayles, 1996; Peel and Wilson, 1996; McIntyre and Coulthurst, 1985; Pattillo, 1981; Grablowsky and Burns, 1980). The remaining 27\% also considered which CBT were used in combination (Andor et al., 2015; Arnold and Panos, 2000; Drury and Tayles, 1996; Peel and Wilson, 1996; McIntyre and Coulthurst, 1985; Pattillo, 1981; Grablowsky and Burns, 1980).

This review makes it clear that a theory-practice gap exists among SMEs. Table 2 shows that the primary CBT used by SMEs is NSCBT, 73\% of all studies (all studies except for Corner, 1967; Williams, 1969; Grablowsky and Burns, 1980; Trahan and Gitman, 1995; Maquieira et al., 2012; Rossi, 2014; 2015), followed by SCBT, 8\% of all studies (Trahan and Gitman, 1995; Maquieira et al., 2012), a mix of both, in 15\% out of all studies (Williams, 1969; Corner, 1967; Rossi, 2014;2015) and that some SMEs do not use any CBT, in 4\% out of all studies (Grablowsky and Burns, 1980).

In defining the size of the SMEs, the studies mainly used two categories: turnover and number of employees. Most of the studies used turnover (Scott et al., 1972; Grablowsky and Burns, 1980; Pattillo, 1981;Runyon, 1983; Trahan and Gitman, 1995; Drury and Tayles, 1996; Arnold and Panos, 2000; Graham and Harvey, 2001; Lazaridis, 2004; Brounen et al., 2004; Maquieira et al., 2012; Harjot o and Paglia, 2012; Lima et al., 2017); some used employees (Soldofsky, 1964; Corner, 1967; Peel and Wilson, 1996; Peel, 1999; Danielsson and Scott, 2006; Rossi, 2014), while a few used both categories (Luoma, 1967; McIntyre and Coulthurst, 1985; Block, 1997; Andor et al., 2015). Others studies provided no information on how they defined the size of SMEs (Rossi, 2015; Vos and Vos, 2000; Williams, 1969).

In terms of location, $46 \%$ of the studies explored SMEs' choice of CBT in Anglo-Saxon countries (Soldofsky, 1964; Luoma, 1967; Williams, 1969; Scott et al., 1972; Grablowsky and Burns, 1980; Pattillo, 1981; Runyon, 1983; Trahan and Gitman, 1995; Block, 1997; Graham and Harvey, 2001; Danielsson and Scott, 2006; Harjoto and Paglia, 2012). In addition, 23\% focused on UK (Corner, 1967; McIntyre and Coulthurst, 1985; Peel and Wilson, 1996; Drury and Tayles, 1996; Arnold and Panos, 2000; Vos and Vos, 2000). Furthermore, 15\% focused on SMEs in Europe (Lazaridis, 2004; Andor et al., 2015; Rossi, 2014; 2015), and a few (8\%) focused on Latin America (Maquieira et al., 2012; Lima et al., 2017). Some studies (8\%) focused on SMEs located in a mix of UK, European and Asian countries (Peel, 1999; Brounen et al., 2004).

\section{Strengths}

One strength in the studies is the context-adjusted definition of SMEs, where the studies performed in UK and US have a higher threshold for their definition of SMEs compared to those performed in Europe. The threshold for the size for an SME among US studies goes up to 1000 employees and $\$ 1000$ in turnover, while in the European studies it ranges between 250 employees (e.g. Rossi, 2014) and as low as 10 (Peel, 1999). Few studies did not use a context-adjusted definition (Maquieira et al., 2012; Brounen et al., 2004), despite focusing non-Anglo-Saxon countries. Instead, they used the US definition (e.g. employees $<1000$ )

to be able to make their study comparable with the results of the US-based studies (e.g. Graham and Harvey, 2001). This creates high transparency when comparing results across the studies. Furthermore, in recent decades, the studies performed on SMEs' use of CBT have been done a greater variety of countries. In the early decades, the studies were done primarily on SMEs in Anglo-Saxon countries (Soldofsky, 1964; Luoma, 1967; Corner, 1967; Williams, 1969; Scott et al., 1972; Grablowsky and Burns, 1980; Pattillo, 1981; Runyon, 1983; McIntyre and Coulthurst, 1985; Trahan and Gitman, 1995; Peel and Wilson, 1996; Drury and Tayles, 1996; Block, 1997).

Furthermore, studies are beginning to provide more details on how the choice of CBT differs among SMEs of different sizes. In the early decades, most studies treated SMEs as members of a single group, but in recent decades, a few studies have distinguished between micro- small- and medium-sized firms (Rossi, 2014:2015). For instance, Corner (1967) shows that small firms prefer using NSCBT while medium-sized firms prefer using SCBT. This is consistent with Rossi (2014:2015), who showed the same 
results. Lastly, many studies have put an emphasis on capturing the combinations of CBT that are used (Grablowsky and Burns, 1980; Pattillo, 1981; McIntyre and Coulthurst, 1985; Peel and Wilson, 1996; Drury and Tayles, 1996; Arnold and Panos, 2000; Andor et al., 2015). The importance of using more than one CBT is argued by Rossi (2014), who suggests that an investment has high legitimacy when it has been evaluated from several angles.

\section{Weaknesses}

A weakness revealed by the analysis is that most of the studies that included both small- and mediumsized firms treated them as a uniform group (44\%) without differentiating the firms' use of CBT. This could be crucial, since the studies that made a distinction in the use of CBT depending on whether the SMEs are small or medium sized, all show that medium-sized firms preferably use SCBT while small firms use NSCBT (Corner, 1967; Rossi, 2014:2015). This indicates that these the SMEs that the firms should not be treated as a single group.

Another weakness is the difficulty in comparing SMEs' results across countries because of the different definitions of size that various researchers use. This makes studies such as those by Brounen et al. (2004) and Maquieira et al. (2012) problematic because they used a US-based definition (\$1000) for countries outside of the US to make their studies comparable with the Graham and Harvey (2001) study. Ang (1991) implies that a small firm in US is more likely to be considered a large firm in Europe, and that therefore are not comparable. Although studies are looking at a greater variety of countries, they are still limited to G8 countries. Such studies represent $85 \%$ of those in this review (Soldofsky, 1964; Luoma, 1967; Corner, 1967; Williams, 1969; Scott et al., 1972; Grablowsky and Burns, 1980; Pattillo, 1981; Runyon, 1983; McIntyre and Coulthurst, 1985; Trahan and Gitman, 1995; Peel and Wilson, 1996; Drury and Tayles, 1996; Block, 1997; Peel, 1999; Arnold and Panos, 2000; Vos and Vos, 2000; Graham and Harvey, 2001; Brounen et al, 2004; Danielsson and Scott, 2006; Harjoto and Paglia, 2012; Rossi, 2014; Rossi, 2015).

\section{Opportunities}

One opportunity in the scope of studies is to explore the perceived benefits of SMEs combining techniques from both NSCBT and SCBT. This is suggested by Rossi (2014), who claims that viewing an investment from more than one angle could help the investment gain legitimacy. Furthermore, a combined use of both NSCBT and SCBT would indicate that the practitioners do not see these techniques as having to be used separately, as has been identified in previous research (e.g. Klammer, 1972). Thus, one opportunity for furthering the field is the development of typologies from the perspective of practitioners. For instance, Sarwary and Umans (2017) suggests a development of new categories by combining NSCBT and SCBT into two new groups. Because, even though scholars make a clear distinction between NSCBT and SCBT (Gitman and Forrester, 1977), it is less likely that practitioners make the same distinction.

There is also opportunity for future research to distinguish between small- and medium-sized firms. This could make a crucial contribution since the few studies that make this distinction show that mediumsized firms are more likely than small firms to use SCBT (Rossi, 2014:2015; Corner, 1967). Furthermore, the use of CBT among SMEs has been highlighted as being important because the SMEs have limited possibilities to diversify their investments into a larger portfolio and to obtain the resources needed to expand (Block, 1997). Hence, it could be crucial to expand the research to include developing countries to capture and the use of CBT for evaluating investments.

\section{Threats}

Continuing the long-term focus on which CBT are being used by SMEs and the extent to which a theory-practice gap exists will not further the field. The focus existed in the early ' 60 s and still does. That focus has had the advantage of presenting a broad picture, but now a different focus is needed. Hence, one should accept that it exists and move beyond it by exploring why these techniques are commonly used by this group of firms. This review also reveals that continuing to treating SMEs as a homogenous group 
could lead to a misleading understanding of which CBT is used, because a comparison between a small firms compare to medium firm do not necessarily choose a primary CBT from the same category, (i.e. NSCBT and SCBT).

\section{Determinants behind the Choice of CBT}

The determinants behind the choice of CBT could be important to identify in order to come closer to understanding under what circumstances the choice of SCBT or NSCBT could be useful. For the purpose of this review, these determinants have been subdivided into four groups: risk assessments, the decision maker, institutional forces and structural characteristics. Around $50 \%$ of the papers explored one or more determinants of the choice of CBT; the remaining 50\% did not include any determinants. See Table 3 for details.

\section{Summary of Findings}

Overall, the studies that explored the determinants of risk assessments on the choice of CBT highlighted two main types of risk that influenced decisions. One type was potential deviation from the forecasting of the investment (Trahan and Gitman, 1995; Danielsson and Scott, 2006; Harjoto and Paglia, 2012; McIntyre and Coulthurst, 1985). The other was the availability of financial from the investment (Soldofsky, 1964; Brounen et al., 2004; Danielsson and Scott, 2006; Maquieira et al., 2012). Some of these studies included both types of risk (Danielsson and Scott, 2006; Maquieira et al., 2012). In general, the results showed that high risk is positively associated with the use of NSCBT, while low risk is positively associated with the use of SCBT.

Overall, the studies that explored determinants related to the decision makers' influence on the choice of CBT show that decision makers' educational level has an influence (Trahan and Gitman, 1995; Brounen et al., 2004; Danielsson and Scott, 2006; Maquieira et al., 2012). The results indicated that a higher level of education and experience is associated with the use of SCBT, while a lower level of education and experience is associated with the use of NSCBT, One expectation are Harjoto and Paglia (2012) who said that experience has no influence on the choice of CBT. In addition, some studies show that the age of the decision maker has an impact on the choice of CBT, where younger decision makers are more likely to use SCBT whereas older decision makers are more likely to use NSCBT. Maquieira et al. (2012), however, showed that there is no relationship between the decision makers' age and the choice of CBT.

The studies that explored institutional forces showed that the national context of the country in which the firm was operating affected the choice of CBT. Anglo-Saxon countries were associated with the use of SCBT (Brounen et al., 2004; Peel, 1999) and domestic subsidiaries were associated with a higher use of SCBT (Peel, 1999; cf Pattillo, 1981). Furthermore, the results show that SCBT is further predicted by whether the firms are shareholder oriented (Brounen et al., 2004) and by shareholder-related factors. For instance, such as stock turnover (Peel and Wilson, 1999), an external board of directors (Harjoto and Paglia, 2012) and whether the firms was highly regulated (Maquieira et al., 2012) or if the firm was operating in financial driven industries (Harjoto and Paglia, 2012). 


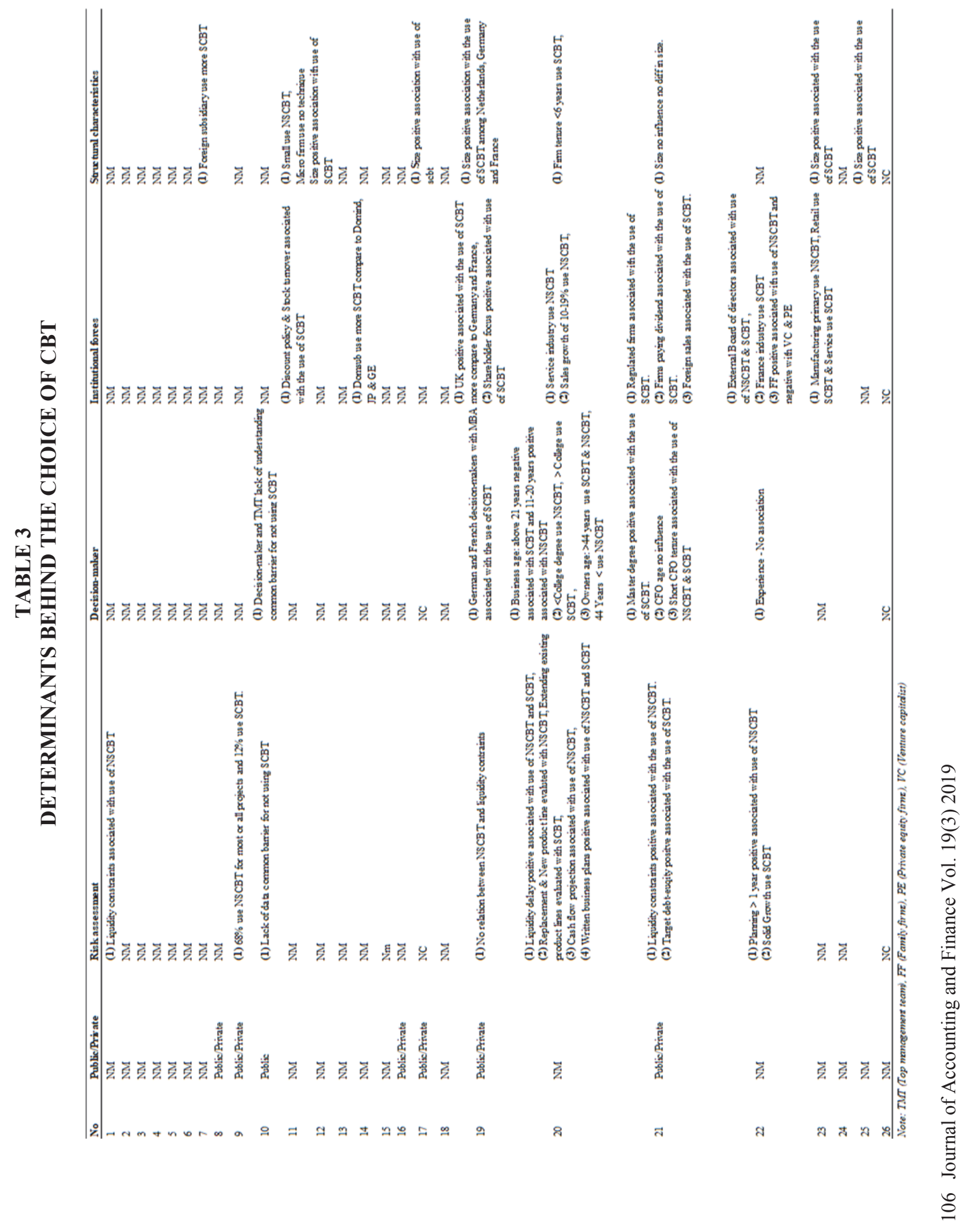


Overall, the studies that explored the influence of structural characteristics showed that the size of the firm has an impact on which CBT was chosen (Peel and Wilson, 1996; Drury and Tayles, 1996; Graham and Harvey, 2001; Brounen et al. 2004; Rossi, 2014:2015). Overall, these studies showed that firms of larger size are positively associated with the use of SCBT. One expectation was Maquieira et al. (2012), who showed that size had no impact on the use of CBT. Danielsson and Scott (2006), furthermore, showed that firm established for less than 6 years are more likely to strive to use SCBT than are older firms. Lastly, the majority of the studies do not mention whether the firms are private or public companies (19 out of 26). One studies included firms that were publically listed and others include both private and public firms (6 out of 26).

\section{Strengths}

The studies done between 1964 and 2004 had been rather narrow in exploring the determinants behind the choice of CBT. However, studies done from 2006 on show an emerging stream of research that adopts an eclectic approach (Brounen et al., 2004; Danielsson and Scott, 2006; Maquieira et al., 2012; Harjoto and Paglia, 2012). This indicates that the field of CBT is flourishing and striving for maturity in understanding how these techniques are chosen. The expansion of the scope of study includes exploration of determinants on an individual level, such as the characteristics of the decision maker (Trahan and Gitman, 1995; Brounen et al., 2004; Danielsson and Scott, 2006; Maquieira et al., 2012; Hrjoto and Paglia, 2012). According to this view, characteristics such as the education and experience are considered to indicate the possibility that the decision maker will adopt more advanced CBT such as the SCBT. Furthermore, the expansion includes exploration of determinants on firm level, such as the capital structure of the firm (Brounen et al., 2004; Danielsson and Scott, 2006; Maquieira et al., 2012) or the size of the firm (Peel and Wilson, 1996; Drury and Tayles, 1996; Graham and Harvey, 2001; Brounen et al., 2004; Rossi, 2014:2015). The firm-level view has recently confronted the theory that SCBT should be used regardless of a firm's context, by showing that, due to characteristics of SCBT such as committing capital long term, SCBT does not suit SMEs that might be constrained in capital. The field has also developed linkages in the choice of CBT on a national level, claiming that, institutional norms in each country might influence these choice, where Anglo-Saxon countries are more likely to strive to use SCBT (Brounen et al., 2004). Research in CBT has learned from the emerging stream of research in entrepreneurship where an eclectic paradigm has enabled the field to gain broad insights. More important, the narrowing of the gap within the field of entrepreneurship might be attributed to the eclectic approach (Audretsch, et al., 2015), towards which the field of CBT might be heading.

\section{Weaknesses}

Despite the increased emergence of research within the field that use an eclectic paradigm, the exploration of the characteristics of CBT that could explain the choice of CBT have been rather narrow. For example, the studies have continued to look at the same determinants, but from different aspects. For instance, the aspect of the decision maker have narrowed to mainly exploring education level and experience (Brounen et al., 2004; Danielsson and Scott, 2006; Maquieira et al., 2012; Harjoto and Paglia, 2012). Exploration of firm-level aspect has mainly focused on size (Peel and Wilson, 1996; Drury and Tayles, 1996; Graham and Harvey, 2001; Brounen et al., 2004; Maquieira et al., 2012; Harjoto and Paglia, 2012; Rossi, 2015) or capital structure (Brounen et al., 2004; Danielsson and Scott, 2006; Maquieira et al., 2012). While the characteristics studied have been diverse, they have not been replicated in more than one study (Trahan and Gitman, 1995; Brounen et al., 2004; Maquiera et al., 2012; Harjoto and Paglia, 2012). For instance, the use of SCBT have long been acknowledged to primarily benefit shareholders (Klammer, 1972) so one could assume that whether the firm is private or public could influence its choice of CBT. As suggested by Ang and Dukas (1991), public companies face a higher pressure to respond to shareholders. Yet, none of the studies had explored whether it mattered if an SME was a private or public company. 


\section{Opportunities}

Given that the current field is simplistic in its structure and has not developed at the same rapid speed as, for instance, research in entrepreneurship (Ekanem \& Smallbone, 2007), it has several opportunities for research. One area is demographic characteristics. The research on decision makers' level of education and

experience indicates that demographic characteristics could help explain CBT choices. Characteristic such as gender and ethnicity, which have been neglected, have also been highlighted as important influences in decisions on investments that are of strategic importance (Brijlal and Quesada, 2008). For instance, females are considered less likely to be risk takers, and thus likely to use NSCBT (Brijlal and Quesada, 2008). Another opportunity would be to explore how social capital predicts the choice of CBT. Social capital has been shown to enhance the possibilities of obtaining information, becoming competent and overcoming capital constraints (cf Brinckmann et al., 2011). A lack of information, competence and capital are commonly perceived as being barriers to using SCBT (Trahan and Gitman, 1995). Further study could explore how they relate to choices made about CBT.Furthermore, the studies showed that availability of credible information is crucial in the choice of CBT (Danielsson and Scott, 2006; Trahan and Gitman, 1995). Thus, there is an opportunity to identify what type of information is crucial when adopting various CBT

Lastly, future studies should focus on whether the firms being a private or public company matters in their choice of various CBT. Ang and Dukas (1991) argues that this might be crucial to consider since a public firm might be more sensitive to shareholder pressure. Moreover, Brounen et al. (2004) shows that the orientation towards different stakeholders matters in the choice of CBT. Thus, an identification of which key stakeholders investments are made in favour of could take the field closer to understanding the effects of coercive isomorphism. Zinkhan and Zinkhan (1994), for instance, criticise the field of CBT for not identifying such powerful stakeholders. They state that research in CBT has mainly favoured shareholders. This could be problematic because stakeholders other than shareholders (e.g. customers, suppliers, other actors on the market and firm environment) have started to emerge as a theme in CBT research, given their potential instrumental value in achieving superior firm performance (e.g. Rivera et al., 2017).

\section{Threats}

The eclectic theoretical framework that has flourished in recent decades could eventually become a weakness if development within the field is not maintained. Efforts to replicate the determinants in the studies might prevent the field from extending its theoretical foundation and considering the complexity which surrounds choices of CBT. As suggested by Northcott (1991), the choice of CBT is associated with different conditions with an interrelated relationship, a situation that needs to be explored from different angles. This involves taking a step from what the scholars consider the practitioners use, to instead understand the circumstances under which practitioners perceive benefits from using SCBT but especially NSCBT. Thus, the main threat the field is currently facing is replicating findings instead of expanding the field of study.

\section{Collection Methods and Analysis}

The collection methods and analysis used in studies can be fruitful or can limit the integration of the practical studies into theory (Brockwell \& Ian R, 2001). This section describes the collection methods used and the analysis of the data in the studies in this review. It presents each paper's useable response rate and the industry to which the majority of sample firms belong. For more information, see Table 4.

\section{Summary of Major Findings}

The collection method most often used in the studies was surveys, which were used in $85 \%$ of the studies (all studies except for Soldofsky, 1964; Pattillo, 1981; Lima et al., 2017), followed by interviews (Soldofsky, 1964; Pattillo, 1981; Lima et al., 2017) and a mixed method (Rossi, 2014). The applied 
analysis of the samples in the studies was descriptive, where the main focus was on presenting the frequency of use of various CBT.

\section{TABLE 4}

\section{COLLECTION METHODS AND ANALYSIS}

\begin{tabular}{|c|c|c|c|c|}
\hline No & Industry & Collection me thod & Analys is & Useable responserate \\
\hline 1 & Manufacturing & Interviews & Qualitative analysis \& Descriptive data & $56,10 \%$ \\
\hline 2 & $\mathrm{NM}$ & Survey & Descriptive data & NM \\
\hline 3 & Manufacturing & Survey & Descriptive data & $54 \%$ \\
\hline 4 & Manufacturing* & Survey & Descriptive data & $24,50 \%$ \\
\hline 5 & Manufacturing & Survey & Descriptive data & $27 \%$ \\
\hline 6 & Retail* & Survey & Descriptive data & 65 \\
\hline 7 & Manufacturing & Interviews & Qualitative analysis \& Descriptive data & 8 \\
\hline 8 & Manufacturing & Survey & Descriptive data & $25,40 \%$ \\
\hline 9 & NM & Survey & Descriptive data & $19 \%$ \\
\hline 10 & NM & Survey & Wilcoxon sign-rank \& Spearman correlation & $13 \%$ \\
\hline 11 & Manufacturing* & Survey & T-test \& Chi-square & $34 \%$ \\
\hline 12 & Manufacturing & Survey & Mann-Whitney & $35 \%$ \\
\hline 13 & $\mathrm{NM}$ & Survey & Descriptive data & $27,29 \%$ \\
\hline 14 & Manufacturing & Survey & Anova \& Chi-square & $21.4 \%$ \\
\hline 15 & NM & Survey & Chi-square & $32,40 \%$ \\
\hline 16 & Service* & Survey & Descriptive data \& Spearman correlation & $6,80 \%$ \\
\hline 17 & Manufacturing* & Survey & T-tests & $9 \% *$ \\
\hline 18 & Construction* & Survey & Descriptive data & $56 \%$ \\
\hline 19 & Manufacturing* & Survey & T-test \& Multivariate regression & $5 \%$ \\
\hline 20 & Retail/Wholesale* & Survey & Binomial z-score \& Multinomial Logit & 792 \\
\hline 21 & Manufacturing* & Survey & T-test \& Descriptive data & $14,30 \%$ \\
\hline 22 & Service* & Survey & Logistic regression & 350 \\
\hline 23 & Service* & Mix method & Descriptive data \& Chi-square & $39 \%$ \\
\hline 24 & $\mathrm{NM}$ & Survey & Descriptive data \& Chi-square & 400 \\
\hline 25 & Service* & Survey & Descriptive data \& Chi-square & $30 \%$ \\
\hline 26 & Agriculture & Interviews & Descriptive analysis & 10 \\
\hline
\end{tabular}

Many of the studies presented results that allowed for comparisons (31\%), where the focus was on comparing the use of CBT across different variables such as size (Peel and Wilson, 1996; Drury and Tayles, 1996; Graham and Harvey, 2001; Brounen et al., 2004; Maquieira et al., 2012; Rossi., 2014:2015); human capital factors (Maquieria et al., 2012; Graham and Harvey, 2001; Brounen et al., 2004); capital structure (Maquieira et al., 2012; Brounen et al., 2004); and the use of CBT across countries (Brounen et al., 2004; Peel, 1999). A few of the studies (11\%) went beyond comparisons and description and used more advanced analysis tools to explore determinants that could predict the use of various CBT. Examples included the effects of external board of directors, investment planning horizons (Harjoto and Paglia, 2012) and the objective of the firm (Brounen et al., 2004).

Most studies looked at firms mainly in manufacturing (46\%) and in the service industry (26\%). A number of studies did not mention which industry the firms belonged to $(27 \%)$. 


\section{Strengths}

Overall, a positive response rate in percentage or in number was reported from the surveys, ranging from $5 \%$ up to $56 \%$, or from 8 to 792 useable respondents. The studies that used interviews as a collection method had 8-10 participants (Pattillo, 1981; Lima et al., 2017; Soldofsky, 1964). In recent decades, the data analysis methods used in the various studies have become more advanced than they were between the early 1960s and late 1990s. When more sophisticated analysis methods are used, the sample size has been large enough (Harjoto and Paglia, 2012; Brounen et al., 2004). Moreover, many studies use analysis techniques that allow for comparison of various variables related to CBT. This has provided insight into how the choice of CBT differs across factors related to human capital (Maquieria et al., 2012; Brounen et al., 2004) and to size (Peel and Wilson, 1996; Drury and Tayles, 1996; Graham and Harvey, 2001). A great many extensive of the studies have focused on manufacturing firms (Soldofsky, 1964; Corner, 1967; Williams, 1969; Scott et al., 1972; Pattillo., 1981; Runyon; 1983; Peel and Wilson, 1996; Drury and Tayles, 1996; Peel, 1999; Graham and Harvey, 2001; Brounen et al., 2004; Maquieira et al., 2012). The emphasis on manufacturing firms has been suggested by several scholars (e.g. Block, 1997) because of the types of investments that sector makes. These scholars imply that the use of CBT becomes more relevant with investments that are of strategic importance. Block (1997) further suggests that the investments made by manufacturing firms are often associated with large and long-term committed capital. This makes the relevance of using CBT high, because when the investments are not of strategic importance the costs of using CBT can be higher than the perceived benefits. Danielsson and Scott (2006) further argue that CBT such as SCBT become relevant once the investments are of strategic importance because of heavy capital commitment and the long time frame. Thus, focusing on manufacturing firms enhances the possibilities of capturing information on firms using both NSCBT and SCBT. Studies have also been done in industries such as construction (Lazaridis, 2004), retail (Grablowsky and Burns, 1980), agriculture (Lima et al., 2017) and service (e.g. Rossi, 2014; 2015; Harjoto and Paglia, 2012; Vos and Vos, 2000).

\section{Weaknesses}

One crucial weakness is that most of the researchers did not provide analysis beyond the descriptive. Thus, many studies have mainly presented the frequencies of use of various CBT (46\%). Furthermore, many of the studies (42\%) used comparison tools to analyse the results; only $12 \%$ used more advanced statistical tools. Consequently, the field has provided a broad picture of which CBT are most popular and extent to which they are used. It has further provided information about how the use of various CBT differs across groups based on variables (e.g. size). However, these studies rarely used the advanced statistical tools that might have enhanced understanding of how various variables predict choices. As a result, the field has failed to widen the use of research methods, which have been dominated by quantitative methods ( $88 \%$ ), with only $12 \%$ consisting of a qualitative approach. The use of a qualitative research method could potentially capture insights and reasoning used in the trade-offs between choosing one CBT over the other, which the field currently lacks.

\section{Opportunities}

An opportunity exists to widen analysis beyond the descriptive by using more sophisticated analysis technique in future research. For instance, previous studies show through simple statistical tools that the firms facing higher liquidity constraints use NSCBT more than firms that did not face the same issue.

However, Brounen et al. (2004), one of the few studies using more sophisticated analysis techniques, showed that variables such as liquidity constraints that had been highlighted as important were of less importance than institutional factors. These factors included whether the firm is shareholder oriented or stakeholder oriented and the institutional setting in which the firm is operating. Instead, the choice of CBT is more likely to be predicted by the orientation the firm has in their objectives.

The field could further benefit from expanding the use of data collection techniques by combining primary data with secondary data, which would allow for rich data analysis. For instance, Graham and Harvey (2001) along with Brounen et al., (2001) provided rich data in their surveys, which consisted of 
usage of CBT, the capital structure of the firm, and firm-level factors, and so on. However, when capturing rich data through surveys, one faces the risk of having low useable response rates (Graham and Harvey, 2001, had a response rate of 9\%, and Brounen et al., 2004, had a response rate of 5\%). To overcome this, a possibility would be to collect the usage of CBT through primary data and to collect firm-specific information from secondary data such as annual reports.

\section{Threats}

A failure to move beyond the descriptive analysis and to provide a comprehensive model developed with advanced statistical methods could lead to stagnation in understanding the CBT chosen by SMEs. The positioning in the field has been limited by the lack of information on why the variables influence the choices of various CBT. Northcott (1991), who has criticised this, argues that the choice of CBT is far more complex than the descriptive normative research suggests, and that the underlying motives that make decision makers trade-off one CBT against another, are difficult to capture through the descriptive. Thus, a shift from descriptive normative research to exploratory research is desirable in order to understand the functions and sophistication of NSCBT as well as of SCBT. One way to address this issue is through the use of a qualitative research method, which has been rather limited in the field. For instance, as Table 1 shows, decision makers use non-formal procedures or, in some cases, gut feelings (Danielsson and Scott, 2006; Scott et al., 1972; Vos and Vos, 2000), while some firms do not use any of the CBT suggested by the researchers (Grablowsky and Burns, 1980). This might indicate that the SMEs face barriers in applying the CBT developed in the literature. For example, McIntyre and Coulthurst (1985) imply that many CBT might possess normative validity, but lack the empirical validity to be useable, because they are far too complex for practical application. Their results further suggest that there is high focus on how decision makers should make choices, rather than on how they actually behave. To understand why some CBT are irrelevant for SMEs, one has to capture respondents' logics, needs and reasoning.

\section{DISCUSSION}

In recent decades, the field of CBT has flourished because of the adoption of an eclectic theoretical framework (Brounen et al., 2004; Danielsson and Scott, 2006; Maquieira et al., 2012; Harjoto and Paglia, 2012). Yet, this eclectic approach could eventually become a weakness if the field does not continue to develop. Some of the opportunities and threats found (Peel \& Bridge, 1998)suggest what can be done to further develop research in the field of CBT.

The finding that several SMEs did not use any CBT (Grablowsky and Burns, 1980; Lazaridis, 2004; Peel and Wilson, 1996) suggests it could be beneficial to explore why the current CBT developed in literature are irrelevant for some SMEs. Moreover, why SMEs make high use of non-financial criteria when evaluating investments should be further explored because it has been neglected due to it having a low legitimacy among scholars' theological rationality (Arnold and Panos, 2000). A continuous normative stream of research that recommends SMEs use SCBT despite their circumstances could lead to a lack of understanding of how SMEs evaluate their potential investments.

Furthermore, an opportunity to further the research exists in the finding show that SMEs more likely will use a combination of NSCBT and SCBT (Grablowsky and Burns, 1980; Pattillo, 1981; McIntyre and Coulthurst, 1985; Peel and Wilson, 1996; Drury and Tayles, 1996; Arnold and Panos, 2000; Andor et al., 2015). This indicates that the practitioners do not see CBT as techniques to be used as separate as has been suggested in previous research (e.g. Klammer, 1972). Thus, the field could develop typologies from the view of the practitioners. Continuing to focus on the extent to which the theory-practice gap exists, instead of exploring which combinations of CBT are useful, will not take the field further. Another opportunity for furthering the research is to distinguish between small- and medium-sized firms. This could be crucial because the few studies that make this distinction show that, compared to small firms, medium-sized firms are more likely to use SCBT (Rossi, 2014:2015; Corner, 1967). Treating SMEs as one group could lead to misleading information about their usage. 
Moreover, continuing to try to replicate the determinants in existing studies might prevent the field from extending its theoretical foundation and considering the complexity that surrounds the choice of CBT. Future studies could, for instance, expand into exploring demographic variables, types of information needed to use various CBT, and the influences of coercive isomorphism.

Lastly, a failure to move beyond descriptive analysis and to provide a comprehensive model developed with advanced statistical methods could lead to stagnation in understanding the CBT chosen by SMEs. The positioning in the field has been limited by the focus on descriptive analysis and the level of differences across variables and the lack of understanding of why these factors influence the choices of various CBT. Thus, a shift from the descriptive normative research to exploratory research is desirable in order to understand the functions and sophistication involved in NSCBT and SCBT. Research could, for instance, adopt more advanced and statistical tools, combine primary and secondary data and expand into using qualitative research methods.

\section{CONCLUSION}

Practitioners' choices of CBT are perhaps one of the most discussed areas in the field of financial management (Harris and Raviv, 1996). This literature review shows which CBT practitioners prefer to use of CBT. Thus, this review provides practitioners with an overview of empirical studies that explore the determinants that influence SMEs' preferences for various CBT, across several countries and contexts. This could take the field a step forward from the normative orientation in approaching research, and help bridge the gap between practitioner's reasons for choosing various CBT and the theory developed to date.

One feature of the field that emerged from the review was the existence of a theory-practice gap among SMEs, in which SMEs were more likely to use NSCBT than SCBT. This could partly be explained by the determinants used, which show a lack of credible data for using SCBT (e.g. Danielsson and Scott, 2006), a lack of understanding of more advanced techniques such as the SCBT (e.g. Trahan and Gitman, 1995), and SMEs possibly being exposed to less institutional pressure than public companies (Vos and Vos, 2000). Moreover, the review shows that the field should expand upon existing models and theoretical frameworks to maintain the eclectic theoretical orientation that has emerged. In addition, the review shows that descriptive research has dominated the field and limited attention has been given to using a qualitative approach, which would allow researchers to explore the trade-offs between choosing various CBT by. A qualitative approach would allow the field to capture the reasoning, logics and the sense making of when there is sophistication in the use of NSCBT as well as in the use of SCBT. This might bring practice closer to theory.

\section{ENDNOTES}

1. According to McMahon \& Holmes (1991), research of CBT among SME first started around 1964.

2. Norwegian list:_https://dbh.nsd.uib.no/publiseringskanaler/Forside?request_locale=en, 1 \& 2 represents journals of scientific level 


\section{REFERENCES}

Andor, G., Mohanty, S., \& Toth, T. (2015). Capital budgeting practices: A survey of Central and Eastern European firms. Emergin Markets Review, 23, 148-172.

Ang, J., \& Dukas, S. P. (1991). Capital budgeting in a competitive environment. Managerial Finance, 17(2/3), 6-15.

Arnold, G. C., \& Panos, H. (2000). The theory-practice gap in capital budgeting: evidence from the United Kingdom. Journal of business finance \& Accounting, 27(5-6), 603-626.

Atkinson, A. B., \& Leigh, A. (2013). The distribution of top incomes in five anglo-saxon caountries over the long run. Economic Record, 31-47.

Audretsch, D., Kuratko, D., \& Link, A. (2015). Making sense of the elusive paradigm of entrepreneurship. Small business economics, 703-712.

Block, S. (1997). Capital budgeting techniques used by small business firms in 1990s. The Engineering Economist, 42(4), 289-302.

Brigham, E. (1995). Fundamental of Financial Management. 7 red. u.o.:Dryden Press.

Brijlal, P., \& Quesada, L. L. (2008, December). The use of capital budgeting techniques in businesses: A perspective from the western cape. Sydney, 21st Australasian Finance and Banking conference.

Brinckmann, J., Salomo, S., \& Georg, H. (2011). Financial Management Competence of Founding Teams and Growth of New Technology-Based Firms. Entrepreneurship Theory and Practice, 35(2), 217-243.

Brockwell, S., \& Ian R, G. (2001). A comparision of statistical methods for meta-analysis. Statistics in medicine, 825-840.

Brounen, D., De Jong, A., \& Koedijk, K. (2004). Corporate finance in Europe: Confronting theory with practice. Financial mangement, pp. 71-101.

Corner, D. (1967). Financial Incentive in the Small Business. Occasional papers in social and economic administration, p. No.5London: Edutext Publications.

Danielsson, M., \& Scott, J. (2006). The capital budgeting decisions of small businesses. Journal of Applied Finance, 16(2), 45-56.

Daunfeldt, S.-O. D., \& Hartwig, F. (2014). What determines the use of capital budgeting methods? Evidence from Swedish listed companies. Journal of Finance and Economics, 2(4), 101-112.

Drury, C., \& Tayles, M. (1996). UK capital budgeting practices: some additional survey evidence. The European Journal of Finance, 2(4), 371-388.

Ekanem, I., \& Smallbone, D. (2007). Learning in small manufacturing firms: The case of investment decision-making behaviour. International Small Business Journal, 107-129.

Gitman, L. J., \& Forrester, J. R. (1977). A survey of capital budgeting techniques used by major US firms. Financial management, 66-71.

Grablowsky, B. J., \& Burns, W. L. (1980). The application of capital allocation techniques by small business. Journal of Small Business Management (pre-1986), 18.000003(50).

Graham, J. R., \& Harvey, C. R. (2001). The theory and practice of corporate finance: Evidence from the field. Journal of financial economics, 60(2-3), 187-243.

Haka, S. F. (2006). A review of the literature on capital budgeting and investment appraisal: past, present and future musings. Handbooks of Management Accounting Research, 2, 697-728.

Harjoto, M. A., \& Paglia, J. (2012). Cost of capital and capital budgeting for privately-held firms: evidence from business owners survey. Journal of Accounting and Finance, 12(5), 71.

Hartwig, F. (2012). The use of capital budgeting and cost of capital estimation methods in swedish companies. Journal of Applied Business Research, 28(6), 1451-1476.

Jackson, S. E., Joshi, A., \& Erhardt, N. (2003). Recent research on team and organizational diversity: SWOT analysis and implications. Journal of management, 29(6), 801-830.

Kaplan, R. S., \& Atkinson, A. A. (1998). Advanced managerial accounting. u.o.:u.n.

Klammer, T. (1972). Empirical evidence of the adoption of sophisticated capital budgeting techniques. The Journal of Business, 45(3), 387-397.

Lazaridis, I. T. (2004). Capital budgeting practices: a survey in the firms in Cyprus. Journal of small business mangement, 42(4), 427-433. 
Lima, A., Da Silveira, J., Matos, F., \& Xavier, A. (2017). A qualitative analysis of capital budgeting in cotton ginning plants. Qualitaitve Research in Accounting \& Management, 14(3), 210-229.

Luoma, G. A. (1967). Accounting information in managerial decision-making for small and medium manufacturers. National Association Accountants, 2.

Maquieira, C., Preve, L. A., \& Sarria-Allende, V. (2012). Theory and practice of cporate finance: Evidence and distinctive features in Latin America. Emergin markets review, 13(2), 118-148.

McIntyre, A., \& Coulthurst, N. (1985). Capital budgeting practices in medium-sized businesses - A survey. Chartered institute of management accountants.

Mukherjee, T. K., \& Al Rahahleh, N. (2013). Capital budgeting techniques in practice: US survey evidence. Capital Budgeting Valuation: Financial Analysis for Todays Investment Projects, 151171.

Naidoo, J., \& Campbell, D. (1988). Canadian South Asian women in transition: A dualistic view of life. Journal of Comparative Family Studies, 311-327.

Northcott, D. (1991). Rationality and decision making in capital budgeting. The British Accounting Review, 23(3), 219-233.

Pattillo, D. M. (1981). Capital investment practices of small manufacturers: American versus multinational. Journal of small business management (pre-1986), 29, 19.000002.

Peel, M. (1999). Planning, business objectives and capital budgeting in Japanese, German and comestic SMEs: some evidence from the UK manufacturing sector. Journal of small business and enterprise development, 6(4), 350-365.

Peel, M., \& Bridge, J. (1998). How planning and capital budgeting improve SME performance. Long range planning, 31.6, 848-856.

Peel, M., \& Wilson, N. (1996). Working capital and financial management practices in the small firm sector. International Small Business Journal, 14(2), 52-68.

Rivera, J. M., Munoz, M. J., \& Moneva, J. M. (2017). Revisiting the relationship between corporate stakeholder commitment and social and financial performance. Sustainable Development, 25(6), 482-494.

Rossi, M. (2014). Capital budgeting in Europe: confronting theory with practice. International Journal of Managerial and Financial Accounting, 6(4), 341-356.

Rossi, M. (2015). The use of capital budgeting techniques : an outlook from Italy. International Journal of Management Practice, 8(1), 43-56.

Runyon, L. (1983). Capital expenditure decision making in small firms. Journal of Business research, 11(3), 389-397.

Sarwary, Z., \& Umans, T. (2017). Puzzling the choice of capital budgeting techniques. Working paper, u.n.

Scott, D., Gray, O., \& Bird, M. (1972). Investing and financing behavior of small manufacturing firms. MSU Business Topics, 20(3), 29-38.

Segelod, E. (1998). Capital budgeting in a fast-chaning world. Long range planning, 31(4), 529-541.

Soldofsky, R. M. (1964). Capital budgeting practices in small manufacturing companies. Studies in the factor market for small business firms, Volym Iowa State University, pp. ed. Luckett DG, Fox KA, Ames, Iowa.

Trahan, E. A., \& Gitman, L. J. (1995). Gridging the theory-practice gap in corporate finance: a survey of chief financial officers. The Quarterly Review of Economics and Finance, 35(1), 73-87.

Verbeeten, F. H. (2006). Do organizations adopt sophisticated capital budgeting practices to deal with uncertainty in the investment decision?: A research note. Management accounting research, 17(1), 106-120.

Williams, R. B. (1969). Industry Practice in Allocating Capital Resources. Managerial Planning, 15-22.

Vos, A., \& Vos, E. (2000). Investment decisoin criteria in small New Zealand businesses. Small Enterpise Research, 8(1), 44-55.

Zinkhan, G. M., \& Zinkhan, C. F. (1994). Capital budgeting: Emerging issues and trends. Managerial Finance, 20(7), 2-9. 